\title{
Patronato regio y preocupación pedagógica en la España del siglo XVIII: El Real Monasterio de la Visitación de Madrid
}

\author{
Gloria A. Franco Rubio *
}

Cuando quedaba ya lejana la época dorada del crecimiento conventual en el conjunto de la sociedad española e incluso parecía que la configuración religiosa de Madrid a nivel parroquial y conventual estaba prácticamente terminada ${ }^{1}$, se produce a mediados del siglo XVIII la erección de un nuevo convento, como fundación real, donde se quiso representar la magnanimidad de la monarquía y su protección sobre la iglesia en una época en la que el laicismo parecía haber cobrado una importancia desconocida hasta entonces, siendo magníficamente dotado a nivel económico gracias a los deseos de la propia fundadora, la reina doña Bárbara de Braganza, esposa de Fernando $\mathrm{VI}$, covirtiéndose en una de las edificaciones más singulares de la ciudad, y cuya construcción correría a cargo de los arquitectos más renombrados del momento, como Carlier y F. Moradillo.

En efecto, la fundación del Convento de las Salesas Reales en esta época responde a una doble consideración: por un lado, se sitúa en la larga tradición de la familia real española de erigir conventos o monasterios bajo su patrocinio, costumbre muy utilizada por los Austrias pero

* Universidad Complutense de Madrid.

En este siglo sólo se crearon en Madrid dos iglesias nuevas, la de San Marcos, mandada edificar por Felipe $V$ para commemorar la victoria de Almansa, y que quedaría como auxiliar de la parroquia de San Martín, y la de San Luis Obispo, creada a mediados de siglo para ayudar en las labores pastorales a la parroquia de San Ginés. Y por lo que respecta a conventos de religiosos sólo se crearían algunas casas de órdenes nuevas (escolapios) a finales de siglo. Franco Rubio, G. A., La iglesia secular de Madrid en el siglo xvili. Un estudio socioeconómico. Madrid 1986. 
que estaba en desuso desde la centuria anterior, y por otro debemos enmarcarla en unas coordenadas nuevas: la importancia concedida en esta centuria a la instrucción en general y a la educación femenina en particular, dado que fue concebido con el objetivo de proporcionar educación a las niñas pertenecientes a la nobleza. Patronazgo real y fomento de la educación, he aquí en curiosa armonía dos aspectos que conjugan a la perfección tradición y modernidad en la España del siglo xvill.

\section{LA FUNDACIÓN DEL CONVENTO-COLEGIO DE LAS SALESAS REALES}

Ya en la escritura de fundación real ${ }^{2}$ la Reina expresa su intención de alzar un convento en la Corte, bajo la advocación de la Virgen, donde ella $u$ otras mujeres pudieran aislarse del resto del mundo siempre que lo necesitaran, al tiempo que fuera un centro de formación donde proporcionar «buena educación y crianza a las niñas nobles para que imbuidas del santo temor de Dios e instruidas de todo lo que corresponde a una persona de distinción, puedan seguir después con felicidad y fruto los designios de la Providencia y cumplir las obligaciones del respectivo estado a que la Divina Voluntad se sirva destinarla" ${ }^{3}$. Dada la inexistencia en España de órdenes religiosas femeninas dedicadas a la enseñanza - los escasos ejemplos que se pueden encontrar en esta época son, en Zaragoza las Ilamadas Hijas de María, establecidas en 1744, las madres Dominicas en Huesca ${ }^{4} 0$ en Málaga el colegio de «Niñas educandas» regentado por las Beatas del Carmen para proporcionar educación a las niñas de la burguesía ${ }^{5}$-, Doña Bárbara pensó introducir en España a la congregación femenina de las salesas, fundada en Francia por San Francisco de Sales y que muy pronto se había extendido por toda Europa desde Polonia a Saboya, pasando por Alemania e Italia, pero hasta ahora desconocida en España, entre cuyos fines destacaba la educación de niñas de buena familia, y que permitía también a las casadas o doncellas poder retirarse a su interior para realizar ejercicios espirituales, y a las personas de avanzada edad o con quebrantada salud poder residir en él ${ }^{6}$.

B.N., Ms. 10.658. Escritura de fundación del real Monasterio de la Visitación de Madrid. Ibidem. Constitución V.

4 Fernández Glemente, E., La llustración aragonesa (una obsesión pedagógica, Zaragoza 1973, págs. 187-195

Reder Gadow, M., «La enseñanza femenina en la Málaga del XVIII," en AA.vV., La mujer en Andalucia. Granada 1990, tomo II, págs. 579-589

G B.N., Ms. 10.658 . 
Para llevar a cabo sus planes, la Reina se dirigió en el año 1747 al primitivo convento de dicha Orden, situado en la ciudad de Annecy, en el Ducado de Saboya, solicitando el envío a España de algunas monjas para desarrollar su ministerio, a las que se habilitaría un convento especial. Habiéndose resuelto afirmativamente la petición de la reina y tras obtener el beneplácito del Ordinario correspondiente, se encaminarían a Madrid Sor Ana Sofía de Riochebardoul, Sor Ana Victoria De Oncieu y Sor María Prospera Truchet, todas profesas, y la novicia Margarita de Crouz. Tras un largo viaje, recorriendo numerosas ciudades, donde habían recibido constantes muestras de afecto, e incluso conocido a la que llegaría a ser su primera pupila ${ }^{7}$, llegaron a la Corte en febrero de 1749 , siendo instaladas provisionalmente (en tanto se les edificara un majestuoso convento) en unas casas situadas en el llamado Prado Viejo, junto al Beaterio de San José, dotada con todo lo necesario para la futura comunidad, en la que se había fabricado la clausura y la correspondiente capilla, a donde se llevaría el Santísimo con el visto bueno del Arzobispo de Toledo, Quintano Bonífaz, así como los cuartos correspondientes a las futuras educandas.

Pronto la comunidad se incrementó con la profesión de algunas Beatas $^{8}$, de modo que tres años más tarde su número había ascendido a catorce monjas, ayudadas por dos novicias, las cuales se encargaban de proporcionar a doce riñas una educación que «les servía más bien de gusto que de trabajo» y que consistía en «seguir la reglita, asistir a los oficios divinos y dar lecciones de catecismo y doctrina cristiana" ${ }^{9}$. Este crecimiento continuó y dos años después la comunidad se había ampliado a veintisiete religiosas mientras que el número de educandas permanecía igual.

Entretando, se iniciaba la construcción del futuro monasterio en unos terrenos comprados por la Reina, junto al paseo de los Recoletos, que

\footnotetext{
Después de buscar documentación sobre este tema en el Archivio General de Palacio, en el de Simancas, en el A. Histórico Nacional y en el del Ministerio de Justicia, donde no parecia haber gran cosa, me dirigí al Convento de las Salesas de Madrid, situado en la calle de Santa Engracia, solicitando tener acceso al archivo o a los fondos documentales históricos que en él se conservaran, pero no fue posible al carecer la comunidad de todo tipo de documentos, según me notificó la hermana portera, si bien se me permitió la consulta del único libro existente sobre la época estudiada: Historia de la Fundación de este primer monasterio de la Visitación de Santa María de Madrid y de los sucesos ocurridos en él hasta nuestros dias. Madrid, tomo I (1749-79).

8 Eran Maria Martín, natural de Villanueva de la Cañada, María Ignacia Vázquez, de Madrid y Mariana Palacios, de Álava. AGP, Sección administrativa, legajo 921-43.

9 «Historia de la Fundación», op. cit
} 
habría de ser, además de casa conventual, colegio, residencia y panteón real, formando un magnífico conjunto que se abría en una plazuela que andando el tiempo tomaría la denominación de Santa Bárbara, en honor de la fundadora ${ }^{10}$. En 1757 estaba terminado $y$, antes de trasladar a la comunidad, la Reina quiso formalizar la escritura pública de fundación real donde se expresaban los compromisos contraídos por ella, como benefactora, y por las monjas como beneficiarias, mediante la formalización de unas reglas o constituciones de funcionamiento que regirían al convento a partir de entonces. En ellas se explica que el Real Monasterio se coloca bajo la advocación de la Virgen, en la Visitación de Nuestra Señora, y estaría formado por una comunidad de treinta y tres religiosas, entre coristas, asociadas y domésticas, cuya dote de ingreso y mantenimiento habitual correría por cuenta de la reina; a pesar de estar exentas de dote, debían aportar cuatrocientos ducados como ayuda de ajuar. Aunque este número era el ideal, dado que las rentas establecidas, como ahora veremos, estaban calculadas para mantener esa cantidad de personas y no más, para poder mantener un nivel de vida adecuado se podrían permitir, en determinadas circunstancias, la entrada de siete más, como máximo, pero ellas, y no la hacienda, estarían obligadas al desembolso de su dote, establecida en tres mil ducados ${ }^{11}$. Todas estas mujeres serian preferiblemente también de grupos sociales elevados, quedando el proceso de selección bajo la tutela de la Cámara de Castilla, por tratarse de una fundación real ${ }^{12}$.

10 Datos referentes a la construcción del edificio, el dinero que costó, la ornamentación que tenía, etc. encontramos en: BN Ms. 10.658; AGP, Sección administrativa, legajo 921; AGP, Sección Reinados (Fernando Vi) C. ${ }^{a}$ 93/3; AHN. Clero, libros 7.920 Y 7.932; AGS, Gracia y Justicia, legajos 700 y 977

${ }_{11}$ Normalmente, los conventos reales solian exigir elevadas aportaciones dotales, alrededor de los dos mil ducados, pero igualmente otros monasterios de menor categoría también pedian dotes importantes: Ios dos de monjas clarisas de la ciudad de Sevilla en 1684 ya cobraban por ella 1.500 ducados de plata, a pesar de ser ésta una época de contracción económica (SÁnchez LoRA, J. L., Mujeres, conventos y formas de la religiosidad barroca. Sevilla 1988) y el Convento de la Canclelaria de Cádiz pedía 2.000 en 1724 ducados (Morgado García, A., "Los ingresos de novicias en el Convento de Nuestra Señora de la Candelaria (Cádiz): 16001900", Gades, n. 15. Cádiz 1987.

12 AGS, Gracia y Justicia, Legajo 700. Hemos encontrado las correspondientes peticiones realizadas por las superioras para poder admitir como profesas a diversas mujeres, para lo que solicitan el beneplácito real:

- Micaela de Arriaga. Corista, 1770.

- Rosa Ducos. Corista, 1771.

- Mariana Ugarte. Corista, 1771.

- Teresa Ortiz de Rosas. Corista, 1771

- María Gertrudis González, viuda de Manuel Francisco Pinel, Consejero del Consejo real de Órdenes, que había sido Camarera de la reina Isabel de Farnesio, y que avalada por la 
En el aspecto monástico y disciplinar se ordenaba el seguimiento perpetuo de la regla de San Francisco de Sales, sometiendo el convento a la jurisdición del cardenal de Toledo, pues era costumbre de esta orden depender directamente de arzobispos, quien delegaría en un Padre espiritual a modo de Vicario o subdelegado para hacer las Visitas pertinentes y demás funciones. También la Superiora y las demás monjas se comprometían a respetar sus propias constituciones y observar su cumplimiento. Dado el carácter de clausura de esta orden, no se permitía la entrada de ninguna mujer a no ser para realizar ejercicios espirituales, por un período máximo de doce días, quedando absolutamente prohibida la admisión de mujeres casadas que se encontraran solas por alguna circunstancia como «causa de divorcio, u otra matrimonial o ausencia del marido» al no estimarse conveniente su presencia ni para las monjas ni para las educandas ${ }^{13}$.

En cuanto al apartado económico, se especifican las cantidades de dinero con que quedaba dotado el convento: la Reina donó 3.095.844 maravedíes en juros y el Rey otros 3.064.674, también en juros, cuyos títulos fueron aportados por ambos, más las aportaciones adicionales de la Marquesa viuda de Ayerbe, que dio 13.115 reales, y la Marquesa de Bondad Real que costeó parte del mobiliario ${ }^{14}$. Igualmente hicieron donación de todos los ornamentos, muebles, enseres domésticos, ajuar y alhajas necesarios, de los que debería hacerse un Inventario. Los títulos de propiedad del edificio conventual, el templo y las casas anejas para los capellanes también fueron registrados en la escritura de fundación y entregadas a las monjas. Para la correcta administración de las rentas se

Condesa de Fuentes solicitó permiso real para ingresar en el convento de seis de mayo de 1773, y se le otorgó el siete de junio del mismo año, recibiendo del Contralor de Palacio quinientos ducados para su dote.

- Gertrudis Arnáiz de las Revillas. Corista, 1776.

- María Remilla de Palacios. Corista, 1776.

- María Ignacia Calzado. Corista, 1779.

- María Andrea Martín Crespo. Doméstica, 1784.

- Juana Centenera. Doméstica, 1784.

- Catalina Martínez. Doméstica, 1784.

- Gabriela Martínez de Baños, 1785.

- María Josefa Zapata y Arbes, natural de Aibar (Navarra), 1796.

- Anastasia María Gallo. Corista, 1796.

- Manuela Borraxo, natural de Caracas, y en aquel entonces porcionista en el Colegio de Leganés; tenía diecinueve años y alegaba ser hija del Capitán Andrés Borraxo, en 1796.

- María Francisca López de Heredia, 1796.

13 BN, Ms. 10.658.

14 Ver cita n. ${ }^{\circ}$ 10, y Demerson, P., Maria Francisca de Sales Portocarrero, Condesa de Montijo. Una figura de la llustración. Madrid 1975. 
preveía la contratación de un Mayordomo que, a cambio de un salario de 2.200 reales anuales, no sólo llevaría las cuentas, sino que trataría de incrementar su patrimonio e invertir el dinero sobrante "en fincas seguras para mayor aumento de las rentas».

Además de las funciones y oficios religiosos que prescribía la regla, las monjas deberian celebrar una cantidad determinada de misas, vigilias, responsos, aniversarios y fiestas por la intención de los patronos fundadores, descritas con todo lujo de detalles, y para su celebración el convento contaría con una serie de ministros eclesiásticos, desde un confesor ordinario que habría de ser «sujeto docto, juicioso, de virtud, prudencia y experiencia» para confesar a las monjas y a las educandas, un primer capellán, «sujeto de literatura, virtud, buenas costumbres, de familia honrada, y graduado de doctor o licenciado", otros cuatro capellanes, un sacristán mayor, que debía ser sacerdote, todos ellos del clero secular y no del regular, un sacristán menor o segundo y cuatro acólitos, que recibirían un sueldo de la Real Hacienda ${ }^{15}$ y que serían sometidos a un riguroso proceso de selección por la Cámara de Castilla ${ }^{16}$, además de ser supervisados por el Arzobispo de Toledo.

En el apartado pedagógico, la constitución $V$ de la escritura especificaba que «siendo uno de los principales fines que nos han movido para esta fundación la buena educación y crianza de niñas nobles, por las grandes utilidades que de esto espero resulten al estado en lo espiritual y temporal: es nuestra voluntad, que se admitan todas las que cómodamente se pudiere, y pareciere conveniente, pero ninguna será recibida, sino que tenga, a lo menos, cuatro años cumplidos y no pase de ocho a nueve, y sin que preceda nuestra licencia, y consentimiento por escrito, y la que lo fuere, deberá llevar su cama, y los demás muebles, que es costumbre, y como hasta aquí se ha practicado, y a todas se las asistirá con el cuidado, amor y caridad que hasta ahora, procurando su mayor adelantamiento; y pagará cada una, al día, de pensión por sus alimentos, dieciséis reales, o lo que se juzgare competente, según las circunstancias» 17 .

15 Los suelos estipulados, todos ellos pagados por la Real Hacienda, eran los siguientes: 11.000 reales anuales al confesor; 7.700 rs. al primer capellán; 5.500 cada una de los demás capellanes; 4.400 el sacristán mayor, que era sacerdote, por lo que recibía un salario mayor al de otros cargos similares; $2.200 \mathrm{rs}$. el sacristán menor o segundo y setenta ducados cada acólito. Además se establecian otros mil reales para los predicadores ocasionales. El mayordomo cobraría 2.200 reales por su trabajo.

16 AGS, Gracia y Justicia, legajo 700. se dice que los capellanes del convento, nombrados en septiembre de 1757 eran Francisco Villa, José Toral, Agustín de Aznárez, Manuel Pingaron, Francisco Antonio Vélez y Feliciano Llopis.

17 BN, Ms. 10.658 . 
Por último, se hacía constar el patronato regio al proclamar patrono perpetuo al rey y sus sucesores, reservándose para ellos determinados privilegios, como ser enterrados en el convento sin que nadie más pudiera hacerlo en el futuro, exceptuándose la familia real, establecer capillas propias, constituir cualquier memoria pía, así como la capacidad de modificar las primitivas constituciones ${ }^{18}$.

Esta escritura de fundación fue formalizada ante notario el día 22 de agosto de 1757, otorgando la licencia eclesiástica el Cardenal Primado, e incluye las firmas de todas las monjas que entonces componian la comunidad, aceptando las cláusulas descritas y comprometiéndose a respetar los deseos de los fundadores. Al final también aparecía la rúbrica de D. Juan Francisco Gaona Portocarrero, Conde de Valparaíso, a la sazón Secretario de Estado y del despacho de Hacienda, quien autorizaba las donaciones correspondientes ${ }^{19}$.

\section{LA EDUCACIÓN FEMENINA EN EL SIGLO DE LAS LUCES}

«Nosotros fuimos los que, contra el designio de la Provindencia, las hicimos débiles y delicadas. Acostumbrados a mirarlas como nacidas sólo para nuestro placer, las hemos separado con estudio de las profesiones activas, las hemos encerrado, las hemos hecho ociosas, y al cabo hemos unido a la idea de sij existencia una idea de debilidad y flaqueza que la educación y la costumbre han arraigado más y más cada día en nuestro espíritu» ${ }^{20}$. Así se refería Jovellanos, una de las figuras más sobresalientes de la llustración española, a la situación en que se hallaban las mujeres de nuestro país a finales del siglo XVIII, una centuria en que la educación y la instrucción habían sido los temas candentes de una gran polémica, objeto de debate por políticos e intelectuales en el seno de la sociedad española. Al mismo tiempo demuestra la paradoja por la que discurría la educación femenina hasta el momento: si por un lado las mujeres habían sido relegadas al ámbito de lo privado, desarrollando sus tareas en un ambiente estrictamente doméstico y familiar sin habérsele proporcionado ninguna posibilidad para cambiar esa situación, debiendo seguir los modelos tradicionales de esposa y madre, por otro, se empezaba a cuestio-

18 Con el tiempo se debieron dar algunas excepciones, ya que hemos encontrado datos de, al menos dos casos, en que antiguas educandas fueron enterradas en el convento.

19 BN, MS. 10.658.

20 Jovellanos, M., "Informe sobre el libre ejercicio de las artes", en Obras Completas. Madrid 1846. Tomo IV. 
nar ese comportamiento suyo, casi siempre superficial, frívolo, inútil, muchas veces inapropiado, incluso pecaminoso a juicio de determinados moralistas, para que también ella se sumara a los nuevos tiempos superando su ancestral incultura y contribuyendo a los cambios que demandaba una sociedad moderna donde tanto significaba la consecución del progreso y frente al cual siempre se había comportado como una verdadera rémora.

En efecto, en la segunda mitad del siglo el debate sobre la educación y la preocupación pedagógica de los ilustrados puso de relieve la deficiente estructura educativa de nuestro país en sus diferentes sectores, por lo que encontraremos una profusa legislación, sobre todo en tiempos de Carlos III y Carlos IV, que permite sentar las bases de una infraestructura adecuada, con la creción de una red de escuelas primarias y secundarias por toda la geografía española y la reforma de la enseñanza universitaria, al tiempo que facilitaba al conjunto de la población el acceso a la instrucción y a la educación, sobre todo tras el decreto que dispone la enseñanza obligatoria. Además de ello, la preocupación del gobierno por fomentar la producción económica, impulsando la creación de establecimientos industriales, puso de relieve la necesidad de disponer de una mano de obra cualificada. De ahí que sobre todo Campomanes se dirija a proporcionar oficios a las masas populares. Por último, la obsesión por el pauperismo y la búsqueda de soluciones para acabar con los desamparados iba a permitir la creación de instituciones benéficas que, con el objetivo de procurarles asilo durante una etapa de su vida que iba desde la niñez a la adolescencia, les daba ocasión para adquirir un oficio, de manera que se les proporcionó la posibilidad de tener una instrucción, no demasiado especializada pero si suficiente para unos grupos sociales que hasta ahora habian estado totalmente marginados de la enseñanza. La conjunción de estos tres grupos de intereses permite hablar de un desarrollo de la educación, sobre todo como enseñanza profesional.

En cuanto a la enseñanza femenina hay que decir que si bien desde principos del siglo XVI la legislación permitía la admisión de las niñas a las Escuelas de Primeras Letras existentes en el país, en la práctica, su asistencia se veía entorpecida por numerosas dificultades. Incluso cuando, a mediados del siglo xVII, el Consejo de Castilla otorgó a la Hermandad de San Casiano el monopolio de la expedición de títulos de maestros, convirtiéndose por lo tanto en una autoridad en materia docente, una de sus primeras manifestaciones consistió en expresar su malestar ante la hipotética educación mixta que se venía impartiendo, y al separar a los 
sexos agudizó las dificultades que hasta ahora tenían las niñas para acceder a la enseñanza ${ }^{21}$.

De esta manera, la atención por la educación se traduciría en numerosas disposiciones dictadas por Carlos III, sobre todo tras la expulsión de los Jesuitas al plantearse a fondo la reforma de la enseñanza a todos los niveles. La primera medida que nos interesa resaltar, y que corresponde a la enseñanza primaria, que es la única donde se acepta la presencia femenina, es un Decreto de agosto de 1768 que ordena el «Establecimiento de casas para la educación de niños, y de las de enseñanza para niñas» donde se advierte desde el primer momento un tipo de enseñanza diferente para los dos sexos, ya que en el caso de las niñas se hace hincapié en el aprendizaje de un oficio, cuando dice que se les enseñaría habilidades propias del sexo, dado que esa incipiente formación estaba dedicada especialmente a hijas de labradores y artesanos ${ }^{22}$. Esta primera disposición sería completada con la Cédula de 11 de mayo de 1783 titulada «Establecimiento de escuelas gratuitas en Madrid para la educación de las niñas, y su extensión a los demás pueblos", que constituye el primer paso en la red posterior de colegios femeninos que se crearían por toda España ${ }^{23}$.

Pronto se advirtió que la cuestión era más compleja de lo que parecía al principio, ya que no se trataba sólo de enseñar, sino de establecer qué clase de educación se habría de dar a esta numerosa población. Y es entonces cuando se pone de relieve o se empieza a cuestionar, casi siempre de manera inconsciente, el papel tradicional de las mujeres, en el que coincidirán tanto intelectuales e ilustrados como moralistas y confesores, todos ellos preocupados por los perjuicios que esa conducta tenía sobre la sociedad española del momento. En este sentido, Carmen Martín Gaite percibe un cambio sutil en la orientación pedagógica hacia las mujeres, señalando cómo a mediados del siglo xvIII a la imagen de la petrimetra vana y gastadora se empieza a contraponer como modelo la mujer hacendosa y maternal frente al acuciante problema de la extendida frivolidad de las mujeres y su general incultura que las hacía incapaces hasta para conversar. No obstante, continua la misma autora, «el asunto de la educación de las mujeres no se centraba tanto en darles acceso al mundo del saber cuanto en tratar de corregir sus costumbres viciadas», de ahí que más que ponerles a su disposición la cultura se tratara de moralizar

21 López-Cordón, M. V., "La situación de la mujer a finales del Antiguo Régimen (1760186)", en Varias Autoras, Mujer y Sociedad en España (1700-1975). Madrid 1982.

${ }_{22}$ Novísima Recopilación de las Leyes de España. Libro VIII, Título I, Ley IX.

23 Ibidem, Ley $X$. 
sus costumbres y proporcionarles unos medios adecuados para ganarse la vida honradamente enseñándoles oficios adecuados a su sexo como la pasamanería, cordonería, tejidos de seda y lana, sastrería para mujeres, confitería, peinados, bordados, encajes y modas. $Y$ es que -termina diciendo - la mujer sabihonda seguía molestando tanto como en la época anterior $^{24}$.

Todo este clima hizo que en el debate general sobre la educación, presente ya en todos los círculos intelectuales y políticos de la época, acabaran planteándose por primera vez qué materias impartir a estas mujeres, lo que desembocaría indefectiblemente en la implantación de una pedagogía diferenciada por géneros, como ya hemos dicho, puesto que al final estaría perfectamente delimitada la instrucción femenina, orientada exclusivamente a la capacitación profesional, sobre todo cuando se trate de proporcionar un oficio a las mujeres del estamento llano, y no en proporcionar una formación intelectual propia de la enseñanza superior, como se había hecho siempre. De hecho, hasta el momento, como indica F. Aguilar Piñal, «la labor educativa respecto a las mujeres comenzaba y terminaba en las escuelas de Caridad, donde las niñas aprendían a coser, hilar, bordar y otras labores propias de su sexo. Era impensable una formación superior para la mujer cuya entrada estaba vetada en las aulas universitarias, en muchos centros de enseñanza secundaria y en la propia Biblioteca Real» ${ }^{25}$.

La cédula citada preveía la creación de escuelas en los diferentes barrios madrileños, cuyo esquema sería posteriormente trasladado al resto del país, donde a las niñas se les ufomentaría la buena educación en las reglas del bien obrar, el ejercicio de las virtudes y las labores propias de su sexo». Esto suponía impartir la doctrina cristiana según el catecismo, enseñar las máximas morales del pudor y buenas costumbres, y en cuanto a las labores se aprenderian desde la elaboración de faja, calceta o punto de red hasta técnicas de costura más esmeradas como bordado, encajes y todo género de listonería. Estas escuelas estaban pensadas como gratuitas para las niñas pobres pero también se preveía la asistencia a ellas de otras niñas cuyos padres podrían pagar una módica cantidad ${ }^{26}$.

Con Carlos IV se crea La Academia de primera educación para rectificar, fomentar y dirigir la enseñanza de la niñez en todos los dominios

${ }^{24}$ Martín Galte, C., Usos amorosos del xvmi español. Madrid 1972 (especialmente el capítulo VIII titulado "La educación de las mujeres»).

25 AgulLAR PIÑAL, F., "La educación al servicio del progreso en el siglo XVIII», en AA.VV: Carlos III y la llustración. Madrid 1988. Tomo I, págs. 45-60.

26 Novísima Recopilación, Libro VIII, Título I, Ley X. 
de S.M. que sería completada con la promulgación del Reglamento de Primeras Letras en 1797 donde toma cuerpo legal la obligatoriedad de la enseñanza a partir de los cinco años y la diferenciación por sexos. En dicho reglamento se invitaba a las Sociedades Economicas a «fomentar y dirigir la Enseñanza primaria, procurando el que los niños fueran educados de un modo correspondiente a la clase y circunstancia de cada uno, y que los hijos de los labradores y menestrales recibieran la enseñanza en el menor tiempo posible para que no lo perdieran y pudieran dedicarse a la agricultura y oficios». De esta manera las escuelas de niños serían propiamente de primeras letras y las de niñas estarían orientadas a la costura, hilado y tejido ${ }^{27}$.

En este contexto habría que aludir a la creación en el pasado de algunos colegios en la principales ciudades, mantenidos por el estado, por instituciones eclesiásticas o por donaciones de particulares, en principio pensados para las niñas huérfanas pero que pronto abririan sus puertas a otras no tan necesitadas cubriendo el vacío existente, como veremos a continuación. En el caso de Madrid, ya existian varios colegios femeninos (Santa Isabel, Monterrey, Leganés, Loreto, la Concepción, el Amparo, etc.) dedicados a proporcionar una elemental educación a las niñas pobres y desamparadas, al tiempo que les servía de casa donde vivir, habida cuenta del desamparo y pobreza en que se encontraban. Sin embargo, aunque estos centros estuvieran dedicados fundamentalmente a albergar a niñas pobres, al ser los únicos donde se podía recibir una mínima educación, fueron ampliando su abanico social dando entrada a niñas de otros grupos sociales. De hecho, el "Colegio de Santa Isabel», fundado por Felipe II en 1595, para recoger a niñas huérfanas y desamparadas entre los siete y los doce años, daba preferencia a las huérfanas de ministros de los Consejos y de los criados de la Casa Real, e incluso en 1605 había empezado a admitir como porcionistas a «niñas de calidad y distinción» pagando sus padres o familiares la correspondiente pensión —nunca menos de tres reales diarios-; allí vivían en clausura y aprendían la doctrina cristiana, lectura, escritura y labores de aguja ${ }^{28}$. El «Colegio de la Purísima Concepción", creado bajo el patrocinio de la Santa y Real Hermandad del Refugio de Madrid, empezó a funcionar en noviembre de 1651, tratando de albergar a las niñas de entre siete y dieciséis años, huérfanas de padre o madre, preferentemente "pobres de solemnidad» ya que, decían sus

27 Aguilar Piñal, F., "La política docente", en AA.W. La época de la llustración. El Estado y la cultura (1759-1808). Madrid 1987, págs. 437-484.

${ }_{28}$ AGS, Gracia y Justicia, Legajo 977: Constituciones del Colegio de niñas huérfanas de Santa Isabel de Madrid 
Constituciones, cen las personas de más calidad es en las que regularmente está la mayor miseria»; andando el tiempo también había permitido la entrada a niñas que tuvieran padre y madre «con tal que procediera el seguero informe de ser personas de nobleza y extremadamente pobres» ${ }^{29}$. A comienzos del siglo XVIII Felipe $V$ decidió crear otro establecimiento similar, el «Colegio de Nuestra Señora del Amparo», cuyos Estatutos fueron aprobados en 1729 para recoger a niñas pobres, y para evitar que sucediera lo que en los anteriores, exigió que debían preferirse siempre las más pobres, huérfanas y desamparadas de padres o parientes a las que lo fueran menos, teniendo que demostrar esa suma pobreza en que se hallaban ${ }^{30}$. En todos los casos citados, para la admisión era preceptivo presentar una partida de bautismo, el certificado de legitimidad en el nacimiento, poseer una apariencia física normal, no ser deformes ni contrahechas, ni padecer enfermedad - especialmente contagiosa- alguna. Una vez admitidas, pasarían en estos colegios las épocas de niñez y adolescencia hasta que estuvieran en condiciones de tomar estado, bien contrayendo matrimonio o ingresando en alguna religión, para lo cual casi siempre el colegio les daría la dote correspondiente.

Fuera de Madrid existían instituciones similares, que fueron multiplicándose a medida que se aplicaba el esquema educativo formulado en la legislación precedente; así, en lugares tan apartados de la Corte como el archipiélago canario, de las treinta y una instituciones educativas existentes sólo en diecisiete se proporcionaba algún tipo de enseñanza a las niñas y esa consistía en doctrina cristiana, lectura, escritura y labores propias de su sexo ${ }^{31}$. En Valencia la educación femenina también se había canalizado a través de escuelas de costuras, de colegios de niñas pobres y huérfanas y por las escuelas de primeras letras fundadas por Carlos III, arrojando una cifra de escolarización muy inferior en el caso de las niñas —ciento cuarenta niños frente a sesenta niñas por aula- ${ }^{32}$. En Huelva, con un grado de analfabetismo del ochenta por ciento, que en el caso de las mujeres se elevaba al noventa, las reformas carolinas no originaron un cambio radical pero permitieron un avance de la enseñanza primaria ${ }^{33}$.

29 AGS, Gracia y Justicia, Legajo 977: Constituciones del Colegio de niñas huérfanas de la Purísima Concepción

30 AGS, Gracia y Justicia, Legajo 977: Constituciones del Real Colegio de Nuestra Señora del Amparo.

31 Santana PÉrez, J.M. y MONzón, M.E., «Instrucción femenina en Canarias durante el reinado de Carlos IIl', en AA.VV. Actas del Coloquio Internacional sobre Carlos III y su siglo. Madrid 1990 , págs. $737-754$

32 López TORıJo, M., Educación y Sociedad en la Valencia llustrada. Valencia 1984.

33 González CRUz, D., "Enseñanza y alfabetización en el siglo de las reformas. Clases sociales y cultura popular en la Huelva del siglo XVIIl», en AA.VV., Actas del Coloquio Internacional sobre Carlos III y su siglo. Madrid 1990, págs. 717-735. 
Finalmente, con el establecimiento de esta red de escuelas primarias por todo el país, a finales de la centuria llegó a haber en toda España noventa y nueve colegios de niños con 4.505 alumnos mientras que solo existían cincuenta para 2.745 alumnas existentes ${ }^{34}$.

Toda esta legislación que hemos comentado y los casos concretos que hemos resaltado abundan en una realidad: proporcionar educación a las niñas pobres y menesterosas. Pero ¿qué pasaba con las pertenecientes a otros grupos sociales, como la burguesía, la nobleza o hijas de funcionarios?. La verdad es que tradicionalmente estas niñas habían recibido instrucción, a veces muy esmerada, en sus propios domicilios, mediante la contratación por sus padres de ayos, preceptores o maestros que les enseñaban lectura y escritura, pequeñas nociones de aritmética, reglas de urbanidad y buenos modales, idiomas, bailes etc., y fuera del propio hogar apenas había centros donde acudir, salvo los casos concretos que hemos reseñado, y que en realidad no habían sido creados para ellas.

Sin embargo, a mediados del siglo xvIII este panorama empezó a cambiar, sobre todo con la introducción por primera vez en España de órdenes religiosas femeninas que se dedicaban a la enseñanza: dominicas, hijas de María y salesas, con lo que las clases medias encontraban un medio de proporcionar educación a sus niñas en un ambiente más refinado que las escuelas citadas. Ya en 1712 Felipe $V$ había creado en Zaragoza un asilo para educar a veinticinco niñas huérfanas de militares donde las llamadas «Hermanas de la Enseñanza» les enseñarían «buenas costumbres y santas virtudes y letras propias y convenientes a su sexo: leer bien en latín y en romance, guardar las reglas de ortografía, contar por tantos y por cifras, leer letra de mano, coser y hacer toda suerte de labores propias de doncellas de su calidad». A fines de la centuria, además de las veinticinco fijas admitían otras niñas de padres «nobles y de distinción» que llevaban allí a sus hijas a recibir educación ${ }^{35}$.

En ese ambiente receptivo a la necesidad de proporcionar educación a un grupo de mujeres que por su pertenencia a la élite habrían de desempeñar un papel importante en la sociedad, como futura esposa y madre pero también como un modelo de mujer nueva, instruida en unos mínimos conocimientos, conocedora de las normas de urbanidad, cultivada en la virtud etc., se inscribe la creación, por parte de la propia reina doña Bárbara de Braganza, del colegio-convento que nos ocupa, y que según sus Constituciones estaría dedicado exclusivamente «a la educación

\footnotetext{
Lopez-Cordón, M. V., op. cit.

Fernández Clemente, E., op. cit.
} 
y crianza de niñas nobles", como ya hemos indicado. Las educandas debían pertenecer a las primeras casas de España, es decir, miembros de los grandes linajes nobiliarios, y podrían vivir en el interior del convento o asistir a diario como porcionistas. La pensión de las internas, que tenían allí su residencia, recibiendo la asistencia de las monjas, consistía en el pago de tres mil reales de una vez y por adelantado al ingresar, más dieciséis reales diarios, cuyo tercio también se tendría que hacer por adelantado para gastos de equipamiento. Debía llevar su propia ropa interior, el uniforme, la ropa de cama (dos colchones, dos fundas, seis sábanas, seis almohadas, dos colchas, dos mantas y una bayeta), los cubiertos y varios libros, todos ellos de carácter religioso o moral, básicos para una buena formación cristiana, como el catecismo de Ripalda, el de San Carlos y el de Fleury, las Conversaciones morales de Flores y el Compendio de la Fe. La instrucción recibida por las niñas incluía el típico plan de la enseñanza primaria -lectura, escritura, nociones de gramática y ortografía, y las cuatro reglas- - pero también rudimentos de lenguas clásicas, el idioma francés, música y labores de costura y bordados, además de la esmerada educación religiosa que hemos visto ${ }^{36}$. Para realizar las distintas labores también deberían traer todo el material necesario, desde agujas hasta dedal y tijeras. Las que asisten como porcionistas, que no vivían allí, debían llevar los mismos libros y útiles de labor, y su pensión era de ocho reales diarios ${ }^{37}$.

Pronto, las familias nobiliarias comenzaron a enviar al colegio sus hijas, no sólo las que tenían su residencia en Madrid sino incluso de lugares tan distantes como Córdoba, Valencia, Cáceres, Logroño, Zaragoza o las Indias también se acostumbraron a enviarlas a él, convirtiéndose este centro en el de mayor prestigio del país por proporcionar la mejor «educación y crianza" que entonces se podía obtener, todo ello acorde al superior status a que ellas pertenecian. De hecho, algunas de sus antiguas alumnas llegaron a alcanzar cierta notoriedad en la sociedad, no sólo por desempeñar óptimamente su papel como damas de la alta aristocracia, sino también desarrollando labores caritativas o de mecenazgo artístico, participando en instituciones reformistas como las sociedades económicas de amigos del país, academias o colegios, traduciendo al castellano obras científicas o filosóficas de autores extranjeros, fomentando tertulias en sus domicilios particulares, escribiendo informes pedagógicos u obras literarias con lo que demostraron poseer unos conocimientos superiores a la

AGP, Sección administrativa, Legajo 921-146 y DEMERSON, P., op. cit.

B.N., Ms. 10.658 . 
mayoría de las mujeres, como podemos comprobar en los pequeños comentarios que haremos a continuación ${ }^{38}$ :

- La primera alumna que ingresó fue la hija del Marqués de la Bondad Real, quien había conocido a las monjas fundadoras en Alcalá de Henares, a donde salió a recibirlas junto a sus padres por encargo de los monarcas durante el viaje de venida a Madrid, momento que aprovechó para hacer la solicitud correspondiente, y que tenía ocho años cuando ingresó ${ }^{39}$.

- María Francisca de Sales Portocarrero, futura condesa de Montijo. Siendo todavía una niña de ocho años, se había quedado huérfana de padre, el Marqués de Valderrábano, y poco después sin la presencia de su madre, que había preferido retirarse del mundo y profesar como religiosa en el Convento de las Maravillas, por lo que su educación y tutela quedaba a cargo de su abuelo paterno. Éste, respetando las disposiciones testamentarias del difunto marqués, cuyo deseo era proporcionar a su hija una educación adecuada a su linaje en el recién estrenado convento, la internó en él, donde permanecería hasta los catorce años, para contraer matrimonio. Ya en el siglo, su fuerte personalidad y su carisma personal la llevaron a convertirse en una de las mujeres más afamadas de la corte, reuniendo en su casa una tertulia donde estaban presentes los más conspicuos intelectuales y los políticos más reformistas del momento, desde donde contribuyó a la propagación de las luces, desarrollando una ingente labor al frente de la Junta de Damas de Honor y Mérito de la Sociedad Económica Matritense, centrada en el interés por la educación de las mujeres, e impulsando la creación de las Escuelas Patrióticas, casi siempre a través de la Comisión Pedagógica, dirigida por ella, donde abogó constantemente por su educación estableciendo las líneas directrices de los nuevos planes de estudio y elaborando memorias sobre las orientaciones pedagógicas a aplicar ${ }^{40}$.

-- Las tres hermanas Pignatelli, hijas del Conde de Fuentes; una de ellas se convirtió en la Duquesa de Villahermosa y otra, Sor María, profesó en este convento en $1762^{41}$.

38 Desgraciadamente, y a pesar de nuestras pesquisas por diferentes archivos y en el propio convento, no hemos encontrado ningún libro de matrículas donde quedasen registradas todas las alumnas que tuvo el colegio en la época que nos ocupa. No obstante, aunque las fuentes nos presentan una información fragmentaria y dispersa, tenemos una investigación en curso sobre dicho alumnado, por eso en estas páginas sólo adelantaremos algunos datos sobre el mismo.

39 "Historia de la fundación», op. cit.

40 Ibidem y DEMERSON, P., op. cit.

41 Ibidem, op. cit. 
- Escolástica de los Ríos y Rohan, hija de los Condes de Fernán Núñez, que entró con tres años, tras la trágica muerte de sus padres, y salió con trece para casarse con el Duque de Béjar. Mantuvo siempre unos lazos estrechos con sus educadoras, a las que hacía periódicas donaciones para el mantenimiento y conservación del convento. Cuando murió, en octubre de 1782, pidió ser enterrada en el convento, en el sepulcro de las monjas, y parece ser que así se realizó, a pesar de que la escritura de fundación prohibía enterrar a nadie que no perteneciera a la familia real ${ }^{42}$.

- María Luisa Centurión y Velasco, marquesa de Villena y Estepa, bienhechora del monasterio y muy conocida en los círculos madrileños ${ }^{43}$.

- María Ignacia Manzo, hija de los marqueses de Bermudo. Estuvo allí siete años como educanda y en 1772 solicitó a la entonces priora Sor Luisa Narváez entrar como religiosa, profesando como corista dos años después ${ }^{44}$.

- La condesa de Puebla del Maestre, que también sería enterrada en la capilla del convento ${ }^{45}$.

- María Felipa Campbell, marquesa de Castejón. Su hermana Juana Francisca fue una de las primeras nobles españolas que había profesado en el convento, convirtiéndose en monja corista en 1750, y en superiora del convento veinte años después (1774-79). Entre las tareas de dirección que tuvo que acometer estaba la facultad de aprobar o denegar las solicitudes de admisión de futuras educandas ${ }^{46}$.

Para terminar, podemos decir que en la sociedad española del siglo XVIII, como en el resto de los países europeos, hubo una enorme preocupación pedagógica que se tradujo en el fomento de la enseñanza a todos los niveles desde las propias instituciones del Estado. A través de una formulación teórica acerca del papel que debía desempeñar la educación en el progreso social y en la modernización del país, se dictó una legislación específica que implantó la enseñanza obligatoria y posibilitó la creación de centros docentes de todas clases, lo que permitió avanzar en la alfabetización del conjunto de la sociedad. No obstante, se perpetuó un sistema educativo basado en la desigualdad y en la discri-

\footnotetext{
Ibidem.

AGS, Gracia y Justicia, Legajo 700

Demerson, P., op. cit.

"Historia de la fundación", op. cit.

lbidem.
} 
minación, tanto de clase - diferenciada por estamentos-como de género.

En cuanto a la educación femenina propiamente dicha, a pesar de los avances constatados, siempre fue una educación diferenciada según el origen y el grupo social, to que desembocó en el nacimiento de una enseñanza "popular", tutelada por el estado, de carácter público, orientada a las niñas del estamento llano y basada fundamentalmente en el aprendizaje de un oficio, junto a una enseñanza elitista, que incidía más en la formación intelectual propiamente dicha, de carácter privado, casi siempre impartida por órdenes religiosas, como en el caso estudiado, y destinada a formar a las niñas de los estratos superiores de la sociedad. 